\title{
Effect of Diflubenzuron on Immature Stages of Haematobia irritans (L.) (Diptera: Muscidae) in Uberlândia, State of Minas Gerais, Brazil
}

\author{
Juliana Junqueira da Silva, Júlio Mendes ${ }^{+}$ \\ Laboratório de Parasitologia, Instituto de Ciências Biomédicas, Universidade Federal de Uberlândia, Caixa Postal 593, \\ 38400-902 Uberlândia, MG, Brasil
}

\begin{abstract}
Horn fly immatures were raised in media containing different concentrations of diflubenzuron in order to verify their susceptibility to this insect growth regulator (IGR). The 50\% and $95 \%$ lethal concentrations of diflubenzuron for the population $\left(L C_{50}, L C_{95}\right)$ were determined as well as the effect of this IGR on the different immature horn fly stages. The tests were performed using the progeny of adults collected in the field. The immatures were maintained in a growth chamber at $25.0 \pm 0.5^{\circ} \mathrm{C}$ and $12-12 \mathrm{~h}$ photoperiod. IGR concentrations of $300 \mathrm{ppb}, 100 \mathrm{ppb}$ and $50 \mathrm{ppb}$ were lethal for $100 \%$ of the sample. Pupae malformation occurred in the breeding media containing different diflubenzuron concentrations. Values for $L C_{50}, L C_{95}( \pm 95 \%$ fiducial limits) and the slope of the regression line were respectively, $25.521 \pm 1.981 \mathrm{ppb}, 34.650 \pm 2.001 \mathrm{ppb}$ and $12.720 \pm 1.096$. The third larval instar was more sensitive to the sub-lethal concentration of the product than the first and second ones were. The results indicate that this IGR can be an important tool for controlling horn fly populations as well as for managing horn fly resistance to conventional insecticides against Haematobia irritans in Uberlândia, State of Minas Gerais.
\end{abstract}

Key words: Haematobia irritans - horn fly - diflubenzuron - insect growth regulator - Uberlândia - Minas Gerais - Brazil

The horn fly, Haematobia irritans (L. 1758) (Diptera: Muscidae) is one of the most important cattle pests in pasture ecosystems (Honer \& Gomes 1990, Kunz et al. 1991). The broad use of conventional insecticides to control this fly has selected resistant populations (Byford et al. 1999, Barros et al. 2001). Therefore, alternative means of control that are not harmful to humans, other animals and the environment, have been sought.

The insect growth regulators (IGR) are a class of products that cause physiologic and morphologic changes during the insect development (Chamberlain 1975, Graf 1993, Lyra et al. 1998). Contrary to conventional insecticides, they present a more restricted action spectrum and do not affect the neural system of the insects (Winslow 1992, Graf 1993). Diflubenzuron is one of the IGR that inhibits chitin synthesis and has ovicidal and larvicidal activity (Grosscurt 1978, Graf 1993). Studies abroad have demonstrated the action of diflubenzuron on the horn fly (Kunz et al. 1976, Hopkins \& Chamberlain 1976, Kunz \& Bay 1977, Schmidt \& Kunz 1980).

The present work aims to verify the susceptibility of $H$. irritans immatures to different concentrations of diflubenzuron, to determine its $50 \%$ and $95 \%$ lethal concentrations to the horn fly $\left(\mathrm{LC}_{50}, \mathrm{LC}_{95}\right)$ and to observe diflubenzuron effect on different immature stages of the horn fly in Uberlândia, State of Minas Gerais, Brazil.

${ }^{+}$Corresponding author. Fax: +55-34-3218.2333. E-mail: jmendes@ufu.br

Received 8 October 2001

Accepted 11 March 2002

\section{MATERIALS AND METHODS}

Collecting horn fly at pastures and obtaining eggs Horn flies were collected using entomological net on Holstein cattle from February 2000 to January 2001 . The dairy cows were kept in a semi-extensive system on a farm, Fazenda Douradinho, $12 \mathrm{~km}$ from the city of Uberlândia $\left(18^{\circ} 55^{\prime} 23^{\prime \prime} \mathrm{S}\right.$ and $\left.48^{\circ} 17^{\prime} 19^{\prime \prime} \mathrm{W}\right)$. Immediately after collection, the flies were transferred to entomological cages (30 by 40 by $33 \mathrm{~cm}$ high) and taken to the Laboratory of Parasitology, Institute of Biomedical Science at Uberlândia Federal University. A moistened filter paper was placed in the cage as an egg laying substratum. A solution of water and sugar ad libitum was offered to the flies that were kept in darkness at a high population density (Mendes \& Linhares 1999). The obtained eggs were removed from the filter paper every $3 \mathrm{~h}$ with the aid of a fine brush (Tigre ${ }^{\circledR}$ n. 0 ) and transferred to flasks containing breeding media.

Preparing breeding media and testing diflubenzuron concentrations - Initially, $3 \mathrm{mg}$ of diflubenzuron (95.34\%) (Champion Farmoquímico Ltda, Brazil) were diluted in $143.01 \mathrm{ml}$ of acetone (Merk®). Aliquots of $15 \mathrm{ml} ; 5 \mathrm{ml} ; 2.5$ $\mathrm{ml} ; 1.75 \mathrm{ml} ; 1.5 \mathrm{ml} ; 1.25 \mathrm{ml}$ and $1 \mathrm{ml}$ of this solution were then added and mixed mechanically for approximately 10 min to $1,000 \mathrm{~g}$ of previously homogenized fresh Holstein cattle manure. This procedure yielded the following diflubenzuron concentrations: $300 \mathrm{ppb}$ (parts per billion); $100 \mathrm{ppb} ; 50 \mathrm{ppb} ; 35 \mathrm{ppb} ; 30 \mathrm{ppb} ; 25 \mathrm{ppb}$ and $20 \mathrm{ppb}$. Correspondent quantity of acetone was added to $1,000 \mathrm{~g}$ of cattle manure to be used as control medium. Both treated and control media were covered with organza and kept at room temperature $\left(25.0 \pm 2^{\circ} \mathrm{C}\right)$ for approximately $12 \mathrm{~h}$ for the acetone to evaporate. Thereafter, $100 \mathrm{~g}$ of treated and control media were transferred separately to the flasks (15 $\mathrm{cm} \times 12 \mathrm{~cm}$ ) containing a layer of approximately $2 \mathrm{~cm}$ of soil previously sterilized. Four replicates of each concen- 
tration and respective controls were used. A total of 50 eggs were then placed on the surface of the breeding media in each of the containers and were kept in a growth chamber (Nova Técnica, Brazil) at $25.0 \pm 0.5^{\circ} \mathrm{C}$ and $12-12$ $\mathrm{h}$ of photoperiod. This material was monitored daily checking the number of emerged adults until 20 days after the last emergence of adults. Thereafter, the media were diluted separately in water for recovery, by flotation, of pupae and empty puparia. These were classified according to their shape in normal and larvae shaped. Pupae and empty puparia considered normal presented morphologic characteristics according to Wharton and Moon (1979).

Susceptibility of horn fly immature stages to diflubenzuron - Eggs were transferred with the aid of a fine brush to Petri dishes containing filter paper moistened with distilled water and a thin layer of fresh manure spread on paper surface. These dishes were kept in a growth chamber at $25.0 \pm 0.5^{\circ} \mathrm{C}$ and $12-12 \mathrm{~h}$ of photoperiod until the larvae hatch.

The sensibility of horn fly immatures of different ages to diflubenzuron was observed by applying two series of tests similar to those used by Hopkins and Chamberlain (1976) and Gingrich and Hopkins (1977). In the first series, 500 hatched larvae with up to 3-h-old were removed from the Petri dishes with the aid of fine brush and transferred to $1,000 \mathrm{~g}$ of medium containing diflubenzuron at $25 \mathrm{ppb}$ and other 500 larvae were transferred to $1,000 \mathrm{~g}$ of control medium. From that point on, 20 immatures were removed from each of the breeding media every $24 \mathrm{~h}$ until the seventh day of development and transferred to flasks containing $25 \mathrm{~g}$ aliquots of control medium. These transfers were done in duplicates with a total of 280 larvae (up to 96-h-old) and pupae (from 120-h-old) transferred from each of the two media to 28 flasks containing aliquots of control medium. This material was maintained in a growth chamber at $25^{\circ} \mathrm{C}$ and $12-12 \mathrm{~h}$ of photoperiod until adult emergence, which were removed, counted and conditioned separately into flasks containing $70 \%$ alcohol.

The procedures used in the second series of tests were similar to those used in the first one except for the fact that the transfers between flasks containing control medium did not occur, and the sequence of immatures' maintenance in the breeding media was the following: 500 newly hatched larvae were maintained initially in the control medium and to each $24 \mathrm{~h}, 20$ of them were transferred to flasks containing medium with diflubenzuron at $25 \mathrm{ppb}$.

Statistical analysis - Probit analysis was applied to calculate $\mathrm{LC}_{50}$ and $\mathrm{LC}_{95}$ of diflubenzuron for the horn fly sample (Finney 1971). In the Probit analysis only those concentrations that were shown to be sub-lethal in the tests were used. Previous to the analysis, the mortality rates obtained for the treated groups were adjusted for the mortality that occurred in the respective control groups (Abbot 1925). A chi-squared goodness-of-fit test was used to check the fit of points to the regression line (Finney 1971).

\section{RESULTS}

The $300 \mathrm{ppb}, 100 \mathrm{ppb}$ and $50 \mathrm{ppb}$ concentrations were lethal for $100 \%$ of the horn fly sample submitted to the treatment (Table I). There was no recovery, by flotation, of any immature fly from the $300 \mathrm{ppb}$ concentration. The larva-shaped pupae were found in the medium treated with $100 \mathrm{ppb}$ diflubenzuron and increased in number as the concentration of the product reduced as low as 35 $\mathrm{ppb}$. The presence of these pupae was not observed in the control medium.

The larva-shaped pupae found were more prolonged and gauged than the normal ones and had sharper segmentations. Some were curved in the anterior region. Larva-shaped pupae measured $4.40 \pm 0.40 \mathrm{~mm}$ on average in length, and normal-shaped pupae measured $3.51 \pm 0.20$ $\mathrm{mm}$.

Imagoes emergence of the larva-shaped recovered pupae from the medium was not observed in $100 \mathrm{ppb}$ and $50 \mathrm{ppb}$ diflubenzuron concentrations. A part of those which originated from the breeding media at concentrations from $35 \mathrm{ppb}$ to $20 \mathrm{ppb}$ resulted in adults (20.3\%). From the $30 \mathrm{ppb}$ concentration, with the reduction of diflubenzuron in the media, there was a gradual reduction in number (from $31 \%$ to $4 \%$ ) and an increase in the number of normal-shaped pupae (from $4 \%$ to $48 \%$ ) down to the lowest tested concentration ( $20 \mathrm{ppb})$.

TABLE I

Adult horn flies emerged from control and treated breeding media containing different concentrations of diflubenzuron in Uberlândia, State of Minas Gerais, Brazil

\begin{tabular}{ccrr}
\hline & Number of eggs placed on each & \multicolumn{2}{c}{ Adult emerged (\%) } \\
\cline { 2 - 3 } Concentration $(\mathrm{ppb})$ & 200 & Treated media & Control medium \\
\hline 300 & 200 & $0(0.0)$ & $126(63.0)$ \\
100 & 200 & $0(0.0)$ & $122(61.0)$ \\
50 & 200 & $0(0.0)$ & $151(75.5)$ \\
35 & 200 & $3(1.5)$ & $143(71.5)$ \\
30 & 200 & $36(18.0)$ & $121(60.0)$ \\
25 & 200 & $56(28.0)$ & $128(64.0)$ \\
20 & 1,400 & $140(70.0)$ & $145(72.5)$ \\
\hline Total & $235(16.8)$ & $936(66.8)$ \\
\hline
\end{tabular}

$a$ : in each tested concentration, four replicates flasks containing 50 eggs per breeding medium, totaling 200 eggs placed on treated medium and 200 eggs placed on control medium as well; ppb: parts per billion 
The susceptibility of the horn fly immatures to diflubenzuron was described by the equation $\mathrm{Y}=12.721 \mathrm{x}$ -12.942 , but the line did not fit to the observed distribution $\left(\chi^{2}=37.29, \mathrm{df}=2, \mathrm{p}<0.01\right)$. $\mathrm{LC}_{50}$ and $\mathrm{LC}_{95}( \pm 95 \%$ fiducial limits), and the slope ( \pm standard error) of the line regression obtained were respectively: $25.521 \pm 1.981 \mathrm{ppb}$, $34.650 \pm 2.001 \mathrm{ppb}$ and $12.721 \pm 1.096$.

Larvae and transferred pupae from one control group to another averaged an emergence of $90.7 \%$ imagoes (Table II). Transferred larvae and pupae from treated medium to control medium, or the reverse, presented considerable reduction in adult emergence. This reduction was shown to be sharper in the groups, where larvae between 48 to $72 \mathrm{~h}$-olds, remained in the medium with diflubenzuron. The pupae also seemed to be affected by diflubenzuron, although less strongly (Table II).

\section{DISCUSSION}

The average percentile of adult emergence obtained from eggs in the control groups were close to those obtained by Schmidt and Kunz (1980) who used a mixture of bovine manure and other ingredients and obtained a 70\% survival rate in immature flies up to the pupa stage. The emergence of adults in part of the larva-shaped pupae indicated that the deformations provoked by the action of the low diflubenzuron concentrations in the pupae were not always lethal. Hopkins and Chamberlain (1976) also reported the presence of malformed $H$. irritans pupae derived from larvae reared continuously in medium treated with diflubenzuron.

The inadequacy of fit of the mortality points to the regression line might have been, in part, due to the heterogeneity of the population submitted to the treatment, which consisted of the F1 generation and not its progeny. Considering that the bioassays were conducted during a year, the population heterogeneity would be also influenced by the temporal aspect (Krafsur et al. 1993, Oliveira et al. 1993).

Small variations in diflubenzuron concentration caused great changes in mortality of the fly. As a consequence, the regression line presented a high slope value. These results could be associated to the fact that this population was not previously exposed to diflubenzuron. The sensitivity of this species to low diflubenzuron concentrations was also verified by Schmidt and Kunz (1980) in Texas (USA) who obtained a close value for $\mathrm{CL}_{50}$ to the one found in the $H$. irritans from Uberlândia. However, the highest slope in this bioassay may be indicative of a higher susceptibility in this population when compared to that studied by those authors (Finney 1971).

Soltani et al. (1989) verified the effects of diflubenzuron from larva to larva and from larva to pupa, as well as in the titers of the ecdisone hormone in Tenebrio molitor (Coleoptera: Tenebrionidae) and suggested that there was a change in the source of the molting hormone at the end of the larval development and that diflubenzuron would inhibit the synthesis of this hormone in the second source. If these considerations are also valid for $H$. irritans, the change in the source of production of the molting hormone and its inhibition would occur before and not at the end of the third stage, since the larvae of this fly were shown to be more susceptible to diflubenzuron action when exposed from 48 to $72 \mathrm{~h}$, the period in which they would be at the third stage but not yet mature (MacLintock $\&$ Depner 1954). These observations are in agreement with Hopkins and Chamberlain (1976) whose experiments of transferring immature horn fly to dung containing diflubenzuron indicated that the beginning of the third larval instar would be the critical period of exposure of the larvae to sub-lethal concentration of this product. Moser et al. (1992) observed mortality in the three larval instars of cat fleas exposed to diflubenzuron and an inverse relationship between the concentration of the product and the affected larval instar was found. Grosscurt (1978) reviewed diflubenzuron action in several species of insects and concluded that in most flies, the last larval instars would be less affected than the first ones. According to this author, the treated larvae can usually feed until the next molt, since death would usually occur during or immediately after the ecdise. Considering that in this bioas-

TABLE II

Adult horn flies emerged after transference of different aged larvae and pupae between control medium and medium treated with diflubenzuron $25 \mathrm{ppb}$ (parts per billion) and vice-versa

\begin{tabular}{|c|c|c|c|c|c|c|}
\hline \multirow[b]{2}{*}{$\begin{array}{l}\text { Age at transfer } \\
\quad( \pm 3 \mathrm{~h})\end{array}$} & \multicolumn{2}{|c|}{$\begin{array}{l}\text { Transfers from control } \\
\text { to control medium }\end{array}$} & \multicolumn{2}{|c|}{$\begin{array}{l}\text { Transfers from treated } \\
\text { to control medium }\end{array}$} & \multicolumn{2}{|c|}{$\begin{array}{l}\text { Transfers from control } \\
\text { to treated medium }\end{array}$} \\
\hline & $\begin{array}{c}\mathrm{Nr} \text { of } \\
\text { immatures } a\end{array}$ & $\begin{array}{c}\text { Adult } \\
\text { emerged }(\%)\end{array}$ & $\begin{array}{c}\mathrm{Nr} \text { of } \\
\text { immatures } a\end{array}$ & $\begin{array}{c}\text { Adult } \\
\text { emerged }(\%)\end{array}$ & $\begin{array}{c}\mathrm{Nr} \text { of } \\
\text { immatures } a\end{array}$ & $\begin{array}{c}\text { Adult } \\
\text { emerged }(\%)\end{array}$ \\
\hline 24 & 40 & $36(90.0)$ & 40 & $38(95.0)$ & 40 & $6(15.0)$ \\
\hline 48 & 40 & $39(97.0)$ & 40 & $37(92.5)$ & 40 & $8(20.0)$ \\
\hline 72 & 40 & $36(90.0)$ & 40 & $26(65.0)$ & 40 & $39(97.5)$ \\
\hline 96 & 40 & $36(90.0)$ & 40 & $23(57.5)$ & 40 & $38(95.0)$ \\
\hline \multicolumn{7}{|l|}{ Pupae } \\
\hline 120 & 40 & $37(92.0)$ & 40 & $22(55.0)$ & 40 & $33(82.5)$ \\
\hline 144 & 40 & $38(95.0)$ & 40 & $16(40.0)$ & 40 & $34(85.0)$ \\
\hline 168 & 40 & $32(80.0)$ & 40 & $16(40.0)$ & 40 & $32(80.0)$ \\
\hline$X$ & 40 & $36.3(90.7)$ & 40 & $25.4(63.6)$ & 40 & $27.1(67.9)$ \\
\hline
\end{tabular}

$a$ : transfer of duplicates containing 20 immatures 
say, the susceptibility of the different immature stages of horn fly to diflubenzuron was observed using a single and sub-lethal concentration, the possibility of higher concentrations of this product to cause mortality in the first larval instars of this fly should not be discarded.

The reduction in the adult emergence when the pupae were transferred from the control medium to the treated medium also suggests the action of diflubenzuron on this stage. Considering that in this phase the fly does not feed, the probable mode of action of the product would be direct contact. According to Grosscurt (1978), diflubenzuron acts mainly when ingested by the larvae, but it can exhibit contact activity. However, there are no reports of action by this product on pupae of this fly (Hopkins \& Chamberlain 1976). In conclusion, the horn fly presents high susceptibility to diflubenzuron in Uberlândia. So, this IGR can be a useful tool for horn fly control as well as to manage resistance to conventional insecticides in the study area.

\section{REFERENCES}

Abbot WS 1925. The method of computing the effectiveness of an insecticide. J Econ Entomol 18: 265-267.

Barros ATM, Ottea J, Foil LD 2001. Horn fly (Diptera: Muscidae) resistance to organophosphate insecticides. Vet Parasitol 96: 243-256.

Byford RL, Craig ME, Derouen SM, Morrison DG, Wyatt WF, Foil LD 1999. Influence of permethrin, diazinon and ivermectin treatments on insecticide resistance in the horn fly (Diptera: Muscidae). Int J Parasitol 29: 125-135.

Chamberlain WF 1975. Insect growth regulating agents for control of arthropods of medical and veterinary importance. $J$ Med Entomol 12: 395-400.

Finney DJ 1971. Probit Analysis, 3rd ed., University of Cambridge, Cambridge, $328 \mathrm{pp}$.

Honer MR, Gomes A 1990. O manejo integrado da mosca dos chifres, berne e carrapato em gado de corte. Embrapa, CNPGC, Circular Técnica, 60 pp.

Gingrich AR, Hopkins DE 1977. Stages of the horn fly susceptible to methoprene. J Econ Entomol 70: 107-108.

Graf JF 1993. The role of insect growth regulators in arthropod control. Parasitol Today 9: 471-474.

Grosscurt AC 1978. Diflubenzuron: some aspects of its ovicidal and larvicidal mode of action and an evaluation of its practical possibilities. Pestic Sci 9: 373-386.
Hopkins DE, Chamberlain WF 1976. Diflubenzuron: relationship betwenn age of exposure immature horn flies and inhibition of maturation. Souwthwest Entomol 1: 114-117.

Krafsur ES, Rosales AL, Robinson-Cox JF, Koehler KJ 1993. Bionomics of pyrethroid-resistant and susceptible horn fly populations (Diptera: Muscidae) in Iowa. J Econ Entomol 86: 246-257.

Kunz SE, Bay DE 1977. Diflubenzuron: effects on the fecundity, production and longevity of the horn fly. Souwthwest Entomol 2: 27-31.

Kunz SE, Schmidt CD, Harris RL 1976. Effectiveness of diflubenzuron applied as dust to inhibit reproduction in horn flies. Souwthwest Entomol 1: 190-193.

Kunz SE, Murrel KD, Lambert G, James LF, Terril CE 1991. Estimated losses of livestock to pests. In D Pimentel CRC Handbook of Pest Management in Agriculture, CRC, Boca Raton, p. 69-98.

Lyra JRM, Ferraz JMG, Silva APP 1998. Acción de inhibidores de la síntesis de la quitina en la reproducción de Spodoptera littoralis (Boisd.) (Lepdoptera: Noctuidae). An Soc Entomol Bras 27: 569-576.

MacLintock J, Depner KR 1954. A review of the life-story and habits of the horn fly, Siphona irritans (L.) (Diptera: Muscidae). Can Entomol 86: 20-33.

Mendes J, Linhares AX 1999. Diapause, pupation sites and parasitism of the horn fly, Haematobia irritans, in Southeastern Brazil. Med Vet Entomol 13: 1-6.

Moser BA, Koehler PG, Patterson RS 1992. Effect of methoprene and diflubenzuron on larval development of the cat flea (Siphonaptera: Pulicidae). J Econ Entomol 85: 112-116.

Oliveira PCS, Trevijano LKG, Bello M 1993. Sensibilidade estacional em linhagens de Musca domestica L. para três tipos de inseticidas. An Soc Entomol Bras 22: 455-461.

Schmidt CD, Kunz SE 1980. Testing immature laboratory-reared stable flies and horn flies for susceptibility to insecticides. J Econ Entomol 73: 702-703.

Soltani N, Delachambre J, Delbecque JP 1989. Stage-specific effects of diflubenzuron on ecysteroid titers during the development of Tenebrio molitor: evidence for a change in hormonal source. Gen Comp Endocrinol 76: 350-356.

Wharton RA, Moon RD 1979. Puparia of Cyclorrhaphous Diptera from bovine dung in open pasture and rangeland on the transition zone of Western North America. Ann Entomol Soc Am 72: 80-89.

Winslow RB 1992. Reguladores de crescimento de insetos e controle da mosca-dos-chifres. A Hora Veterinária 11: 38-40. 